\title{
Lymphocytes and macrophages of the epidermis and dermis in lesional psoriatic skin, but not epidermal Langerhans cells, are depleted by treatment with cyclosporin $A^{*}$
}

\author{
A. K. Gupta ${ }^{1}$, O. Baadsgaard ${ }^{1}$, C. N. Ellis ${ }^{1}$, J. J. Voorhees ${ }^{1}$, and K. D. Cooper ${ }^{1,2}$ \\ 1 Department of Dermatology, University of Michigan Medical Center, \\ 2 Dermatology Service, Ann Arbor Veterans Administration Hospital, Ann Arbor, Michigan, USA
}

Summary. Since cyclosporin A (CsA) is an immunosuppressive agent, its beneficial effect in psoriasis suggests that immune cells may play a role in the pathogenesis and resolution of psoriasis. To determine early effects of CsA in psoriasis, we quantitated immune cells using double immunofluorescence microscopy on biopsy specimens obtained prior to therapy and after 3,7 , and 14 days of CsA therapy. CsA therapy resulted in significant reductions in the absolute number of immune cells (including $\mathbf{T}$ cells, monocytes/macrophages, and antigen presenting cells) contained within psoriatic skin. The effect was rapid, with over one-half of the reduction in the density of $\mathrm{HLe1}^{+}$(human leukocyte antigen-1 positive or bone marrow derived) cells, including $T$ cells, activated $T$ cells, monocytes, and Langerhans cells (LCs), occurring within 3 days. Despite the overall reduction in the numbers of immunocytes in the skin, the proportion of $T$ cells, Langerhans cells, and monocytes in relation to the total number of immune cells was unchanged with therapy, reflecting equally proportional losses of each subtype. Dermal $\mathrm{CD1}^{+} \mathrm{DR}^{+}$cells (putative Langerhans cells), which are not found in normal skin but are present in lesional psoriasis skin, were virtually cleared from the papillary dermis after CsA therapy. Although absolute numbers of epidermal Langerhans cells, defined as cells expressing both CD1 (T6) and DR molecules $\left(\mathrm{CD}^{+}{ }^{+} \mathrm{DR}^{+}\right)$, were also reduced after CsA, epidermal non-Langerhans $\mathrm{CD1}^{-} \mathrm{DR}^{+}$cells (macrophages, activated $\mathrm{T}$ cells, $\mathrm{DR}^{-}$keratinocytes) demonstrated a proportionally greater decrease, with the ratio of $\mathrm{CD1}^{+} \mathrm{DR}^{+}$Langerhans cells/non-Langerhans $\mathrm{CD1}^{-} \mathrm{DR}^{+}$epidermal cells changing from a mean of 0.82 at baseline to 1.92 at day 14 . Thus, early in the course of therapy, CsA appears to be effective at clear-

\footnotetext{
* This work was supported in part by the Babcock Foundation Offprint requests to: Kevin Cooper, MD, Department of Dermatology, Immunodermatology Unit, Kresge I R5538, University of Michigan, Ann Arbor, Michigan, 48109, USA
}

ing $\mathrm{CD1}^{-} \mathrm{DR}^{+}$cells while leaving $\mathrm{LC}$ relatively intact in the epidermis.

Key words: Cyclosporin A - Psoriasis - Antigen presenting cells - Monoclonal antibodies - T cells Monocytes - Langerhans cells

Psoriasis is a common inflammatory disorder, probably of multifactorial etiology, affecting approximately $2 \%$ of the population in the United States of America. We recently carried out a randomized, double-blind trial in which cyclosporine A (CsA), administered at a dose of $14 \mathrm{mg} / \mathrm{kg} /$ day, caused dramatic improvement in 20 of 21 psoriatic patients within 4 weeks [1]. Since CsA has immunosuppressive effects, this raised the possibility that cellular immune processes may play a role in the pathophysiology of psoriasis. Analysis of changes in immune cellular elements present in lesional psoriasis skin may help elucidate the mechanism of action of CsA in psoriasis.

In six consecutive patients, we performed quantitative single and double immunofluorescence microscopy using monoclonal antibodies directed toward leukocyte subsets in order to characterize immune cellular changes that occur within the epidermal and dermal infiltrate at various times after initiation of oral CsA therapy. Baker et al. [2] have looked at changes in immune cell types in psoriatic lesions treated with CsA at time intervals ranging between 10 and 90 days after CsA therapy. Since we saw clinical improvement in most patients by 10 days of CsA therapy $(14 \mathrm{mg} / \mathrm{kg} /$ day $)$ [1], we decided to investigate the changes in immune cell types prior to clinical improvement being obvious. In addition, we correlated clinical improvement with the nature and flux of the infiltrate. Here, we report that CsA induces changes in activated 
$\mathrm{T}$ cells, antigen presenting cells (APCs) and monocytes, expressed as both absolute density of cells in the tissue and as relative percentages of total leukocytes within 7 days of CsA therapy.

\section{Materials and methods}

\section{Patients}

Six consecutive patients (all males), treated with CsA $14 \mathrm{mg} / \mathrm{kg}$ / day for 4 weeks, were studied for immunophenotype analysis. Their mean age was 45 years (range, 32 to 61 years). Patients had greater than $20 \%$ body surface area involved and had been unresponsive to conventional therapies. The psoriasis had been stable in extent and severity for at least 2 weeks. The patients had not used systemic or intralesional corticosteroids, or ultraviolet (UVB or PUVA) therapy for at least 4 weeks, nor topical therapy, except bland emmolients, for at least 2 weeks prior to entry into the study. Patients were at least 18 years old and in good health on the basis of history and physical examination. Clinical evaluation of psoriasis was made at pretherapy, after the 3rd and 7 th days of therapy, and then at weekly intervals.

The protocol and consent had been approved by the University of Michigan Medical Center institutional review board. The Food and Drug Administration had approved our physician's investigational drug application. All the patients gave informed consent after the nature of the study had been fully explained.

\section{Fluorescence microscopy}

In 3 patients, 6-mm punch biopsy specimens were taken from representative psoriatic plaques at pretherapy and after 3 and 7 days of CsA therapy, and in three patients at pretherapy and after 7 and 14 days. Punch biopsy specimens were obtained following local anesthesia with $1 \%$ lidocaine with epinephrine. These were embedded in Tissue Tek II O.C.T. compound (Miles Laboratories, Naperville, Ill.) and were rapidly frozen and stored at $-70^{\circ} \mathrm{C}$. Subsequently, 6- $\mu \mathrm{m}$ sections were cut on a cryostat, mounted on albuminized slides, and air dried.

In order to determine the type and intensity of the epidermal and dermal infiltrate, a battery of monoclonal antibodies was employed. HLe1 is a surface antigen expressed on all human bone marrow derived cells (leukocytes; Becton Dickinson, Mountainview, Calif). Leu1 detects a pan T cell antigen (CD5) on human peripheral and thymic $\mathrm{T}$ cells (Becton Dickinson). OKT6 stains the cell-surface antigen CD1 on cortical thymocytes and Langerhans cells (LCs; Ortho Diagnostic Systems). Anti HLA-DR (Becton Dickinson) binds to class II major histocompatibility complex proteins of LCs, B cells, activated T cells, monocytes, and interferon gamma-exposed keratinocytes. Mono1 is a monocyte antigen marker (Bethesda Research Laboratories (BRL), Bethesda, Md.).

For single label immunofluorescence, 6 - $\mu \mathrm{m}$ frozen sections of psoriatic tissue were incubated with optimal dilutions of the primary antibody for $45 \mathrm{~min}$ at room temperature, washed three times in phosphate-buffered saline (PBS) at $\mathrm{pH} 7.6$, followed by a 30-min incubation with second step fluorescein-conjugated antibody (goat anti-mouse IgG antibody, heavy and light chain specific, affinity purified and human serum adsorbed; Kirkegaard and Perry, Gaithersburg, Md.). For double label immunofluorescence microscopy, one primary antibody was fluorescein-conjugated and the other primary antibody was biotin-conjugated. The second step reagent was Texas Red conjugated to streptavidin (Bethesda Research Laboratories). In some cases, a three-step method was used, which consisted of the primary antibody (first step) which was visualized with rhodamine-conjugated goat anti-mouse IgG (second step) and then a second directly fluoresceinated antibody to a separate determinant was mixed with normal mouse serum and applied to the tissue (third step). The mouse serum prevents binding of the rhodamine goat anti-mouse IgG antibody to the third step antibody. The sections were coverslipped in PBS containing $50 \%$ glycerol and visualized using a Nikon Optiphot microscope equipped with epifluorescence, appropriate filters, and double exposure photographic capabilities. For each specimen, the density of cells stained by the various monoclonal antibodies was counted in at least 10 high power fields (hpf; 1.4 linear $\mathrm{mm}$ of skin) and the average obtained. When sections stained with antiCD1 antibody were examined, only dendritic cells exhibiting the cytoplasm and nucleus were counted as positive; dendrites without the main cell body were not included [19].

\section{Statistical evaluation}

In order to determine whether the degree of infiltrate (absolute density per $\mathrm{mm}$ ) of the various phenotypes had changed significantly between baseline and days 3 and 7 , a paired $t$-test was used. This test was also used to evaluate whether the phenotypes Mono1, Leu1, Leu1 ${ }^{+} \mathrm{DR}^{+}, \mathrm{CD}^{+}{ }^{+} \mathrm{DR}^{+}$, and $\mathrm{CD} 1^{-} \mathrm{DR}^{+}$expressed as a ratio of $\mathrm{HLe}^{+}{ }^{+}$, had changed significantly between baseline and day 7 . We also determined, using Pearson's correlation analysis, whether there was a relationship between clinical lesion scores and a change in certain cell phenotypes. All $p$ values are two-sided unless otherwise stated.

\section{Results}

The mean number of cells/hpf in the epidermis and dermis of the six patients at days 0 (baseline) and 7 of CsA therapy is shown in Figs. 1 and 2 respectively. Lesional psoriasis skin contained a large number and variety of infiltrating leukocytes. In addition to LCs, non-Langerhans $\mathrm{CD}^{-}{ }^{-} \mathrm{DR}^{+}$cells were present in psoriasis epidermis (Fig. $3 \mathrm{a}, \mathrm{b}$ ). HLe1 $^{+}$cells (bone marrow-derived leukocytes) were present in the epidermis and dermis, and were comprised of Leu1 ${ }^{+} \mathrm{T}$ cells (Fig. $4 \mathrm{a}, \mathrm{b}$ ), activated (DR ${ }^{+}$) T cells (Fig. 5a,b) and monocyte/macrophage derived cells (Fig. 5c).

CsA therapy resulted in a marked decrease in these cell types from the skin (Figs. $4 \mathrm{c}$, d and $5 \mathrm{~d}-\mathrm{f}$ ). Absolute cell counts of each phenotype were performed to quantitate the degree of clearing (Figs. 1 and 2). Between days 0 and 7 , in the epidermis, there was a significant decrease $(p<0.01)$ of bone marrow-derived cells, whether calculated as the number of $\mathrm{HLe}^{+}$cells or as the total of Leu1, Mono1 and $\mathrm{CD} 1{ }^{+} \mathrm{DR}^{+}$cells. There were also significant decreases in the number of HLe1 ${ }^{-} \mathrm{DR}^{+}$keratinocytes, Mono1 ${ }^{+}$ macrophages, Leu1 ${ }^{+} \mathrm{T}$ cells, Leu $1^{+} \mathrm{DR}^{+}$activated $\mathrm{T}$ cells, $\mathrm{CD}^{+} \mathrm{DR}^{+} \mathrm{LCs}$ and non-Langerhans CD1 ${ }^{-} \mathrm{DR}^{+}$cells (Fig. 1).

In the epidermis, $\mathrm{HLe}^{-} \mathrm{DR}^{+}$cells identify keratinocytes, presumably induced by gamma-interferon to express HLA-DR. These decreased by $47 \%$ 

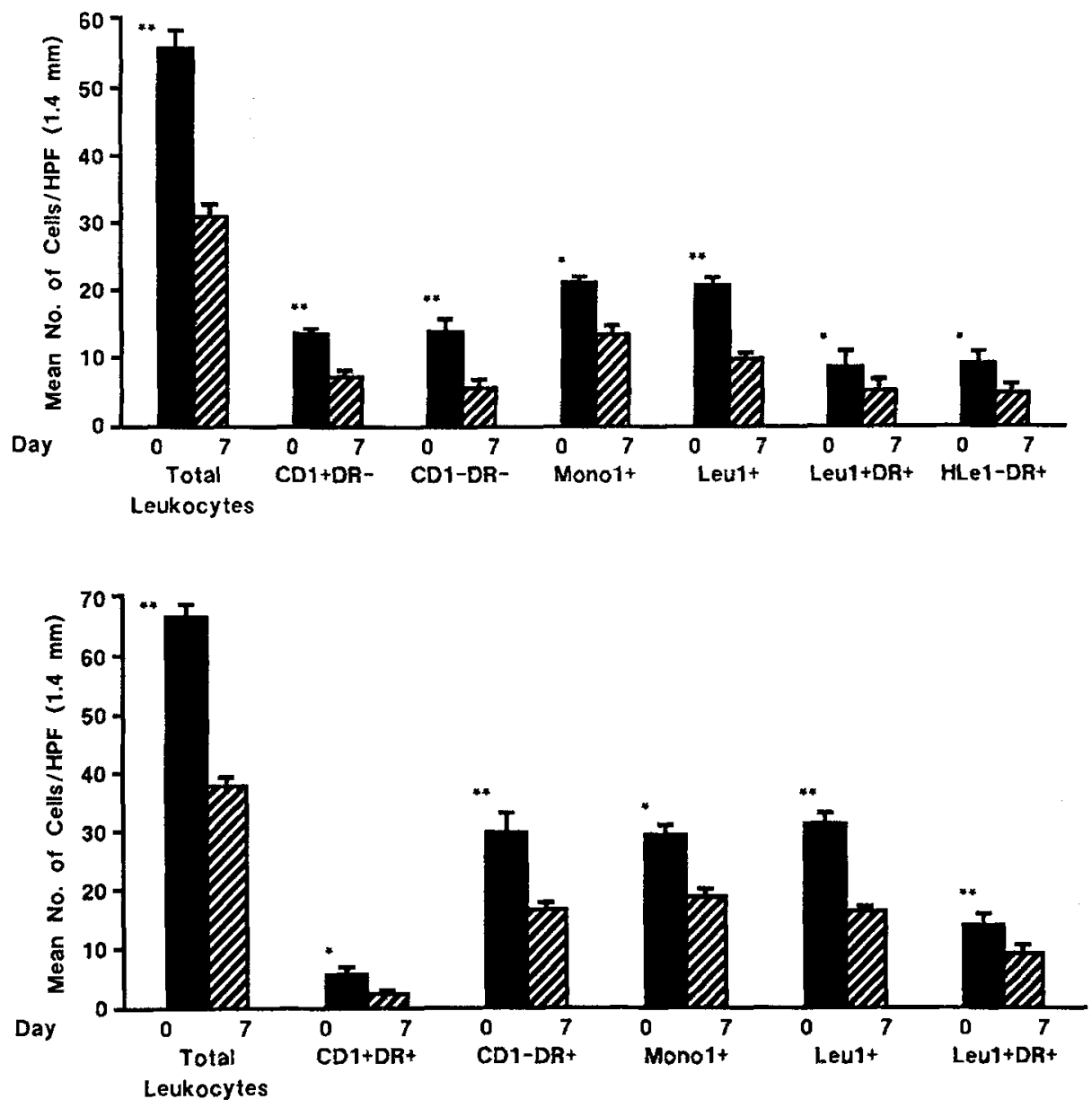

Fig. 1. Absolute number of cells of the various phenotypes in the epidermis before and after 7 days of CsA therapy. Number of cells expressed per hpf (linear $1.4 \mathrm{~mm}$ ) $\pm \operatorname{SEM}(n=6) . * p<0.05$ ** $p<0.001$

Fig. 2. Absolute number of cells of the various phenotypes in the dermis before and after 7 days of CsA therapy. Number of cells expressed per hpf (linear $1.4 \mathrm{~mm}) \pm$ SEM $(n=6),{ }^{*} p<0.05, * * p<0.001$

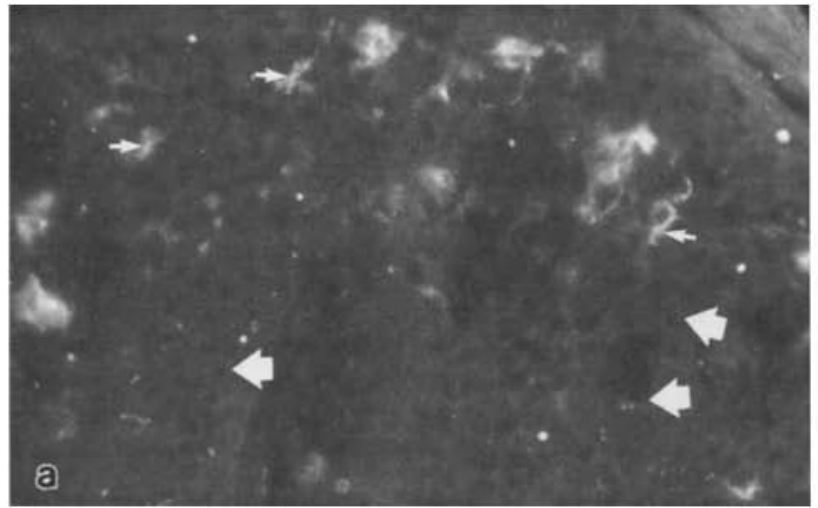

Fig. 3a,b. Expression of CD1(T6) (a) and HLA-DR (b) at pretherapy. Small arrows denote epidermal Langerhans cells expressing both CD1(T6) (a) and HLA-DR (b). Large arrow de-

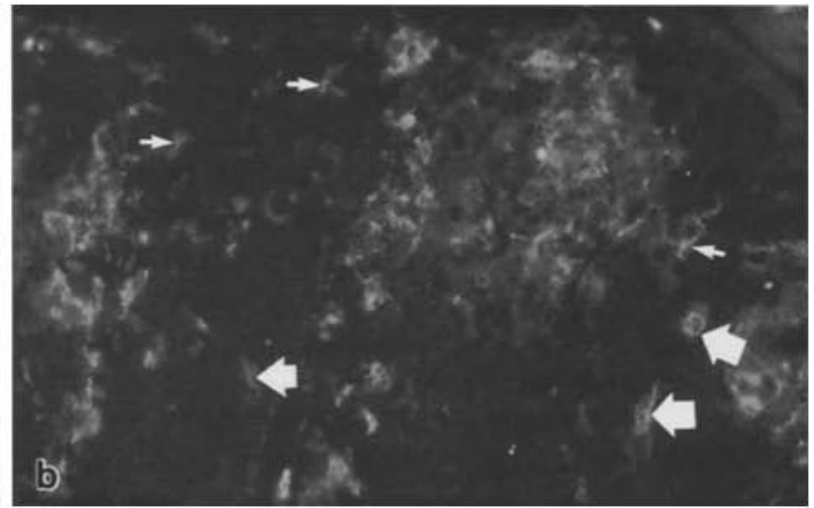

note cells expressing HLA-DR (b) but not CD1(T6) (a). These include macrophages, indeterminate cells and activated $T$ cells. (Original magnification $\times 50$ )

epidermal non-Langerhans $\mathrm{CD} 1^{-} \mathrm{DR}{ }^{+}$cells demonstrated a proportionally greater decrease than did $\mathrm{CD} 1{ }^{+} \mathrm{DR}{ }^{+} \mathrm{LCs}$, with the ratio of $\mathrm{CD} 1^{+} \mathrm{DR}^{+} \mathrm{LCs}$ to $\mathrm{CD} 1^{-} \mathrm{DR}^{+}$cells changing from a mean of 0.82 at baseline to 1.92 at day 14 . 

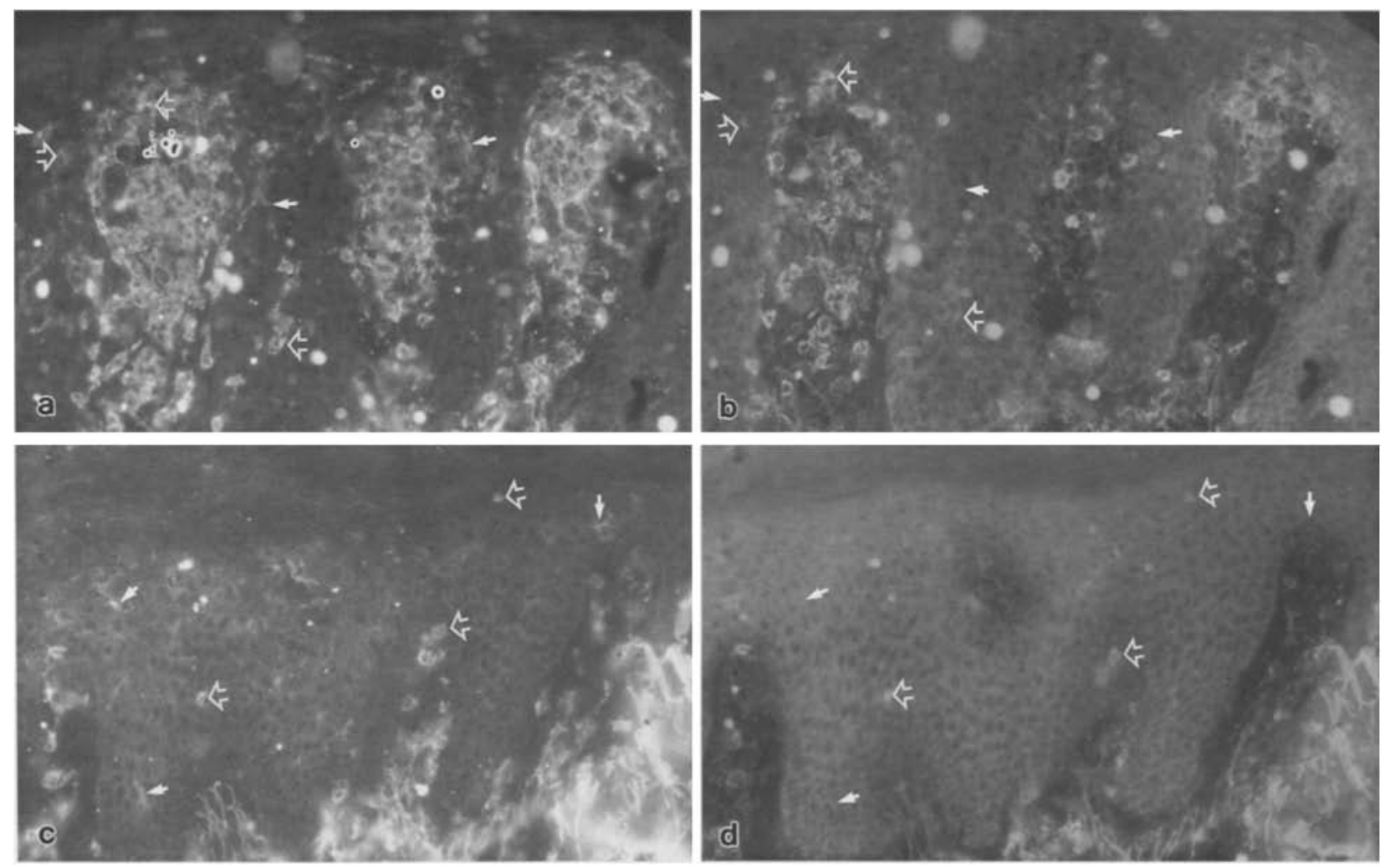

Fig. 4a-d. Distribution of infiltrating leukocytes contained in involved psoriasis skin at pretherapy $\mathbf{a}, \mathbf{b}$ and after 14 days of CsA therapy c, $\mathbf{d}$. (Original magnification $\times 50$ ); a Intense infiltrate of HLe1 ${ }^{+}$(bone marrow derived) and b Leu1 ${ }^{+}$( $\mathrm{T}$ cells) in psoriasis skin at pretherapy. Open arrows denote cells expressing both HLe1 a and Leu1 b. (HLe1 ${ }^{+}$Leu ${ }^{+}$cells). Closed arrows denote cells expressing HLe1 a but not Leu1 b. (HLe1 ${ }^{+}$Leu $^{-}$

In the dermis at day 0 , bone marrow derived cells $\left(\mathrm{HLel}^{+}\right)$were comprised of monocytes, $\mathrm{T}$ cells and $\mathrm{CD} 1^{+} \mathrm{DR}^{+}$cells which may be Langerhans cells (Figs. 2, 3). As in the epidermis, significant reductions in the absolute numbers of infiltrating cells in the dermis were observed after CsA therapy. Compared with untreated psoriasis skin, the absolute numbers of dermal CD $1^{+} \mathrm{DR}^{+}$Langerhans cells decreased by $66 \%$ over the 1st week of CsA therapy, and by day 7 of therapy, these cells were rarely seen. Although the density of all $\mathrm{T}$ cells was reduced at day 7 (Fig. 2), the mean percentage decrease of activated $\mathrm{T}$ cells $\left(\mathrm{DR}^{+} \mathrm{Leu}^{+}\right)$was only $30 \%$, compared to a $66 \%$ decrease of nonactivated $\mathrm{T}$ cells $\left(\mathrm{DR}^{-} \mathrm{Leu}^{+} ; p<0.05\right)$. Persistence of $\mathrm{DR}^{+} \mathrm{Leu}^{+} \mathrm{T}$ cells was also observed in the epidermis.

If clearing of immunocytes from the skin is important to the mechanism of CsA action in psoriasis, then the cells should show a brisk response which is followed by clinical improvement. In order to assess the rapidity of disappearance of individual

cells). These include macrophages and Langerhans cells. c Marked reduction in infiltrate of $\mathrm{HLe}^{+}{ }^{+}$(bone marrow derived) cells and $\mathbf{d ~ L e u} 1^{+}$(T cells) at day 14 of CsA therapy. Open arrows denote cells expressing both HLe1 a and Leu1 b. (HLe1 ${ }^{+}$Leu ${ }^{+}{ }^{+} \mathrm{T}$ cells). Closed arrows denote cells expressing HLe1 a but not Leu1 b. (HLe1 ${ }^{+}$Leu1 ${ }^{-}$cells). These include macrophages and Langerhans cells

cell types, changes in the absolute numbers of cells/ hpf between pretherapy and days 3, 7, and 14 were expressed as the percent decrease in the absolute numbers of cells/hpf relative to day 0 . For example, the percentage decrease in Leu1 cells at days 3, 7, and 14 of therapy were $42 \%, 49 \%$, and $61 \%$ respectively. The majority of the loss of leukocytes (Leu $1^{+}$, Mono $1^{+}$, and $\mathrm{CD}^{-} \mathrm{DR}^{+}$) occurred within the first 3 days of CsA therapy (mean decrease that occurred during the first 3 days expressed as a percentage of the decrease that had occurred during the first 14 days of therapy was $63 \%$ ). $\mathrm{DR}^{+}$keratinocytes $\left(\mathrm{HLe}^{-} \mathrm{DR}^{+}\right.$) demonstrated a somewhat slower decrease in the absolute numbers of cells per hpf relative to baseline of $30 \%$, $52 \%$, and $86 \%$ at days 3,7 , and 14 of CsA therapy respectively.

Clinical lesion scores demonstrated a $30 \%, 52 \%$, and $70 \%$ decrease (relative to pretherapy) at days 3 , 7 , and 14 , respectively, following CsA therapy. Thus, although it is difficult to compare clinical lesion score data with cellular immunopathology quantitations, it 

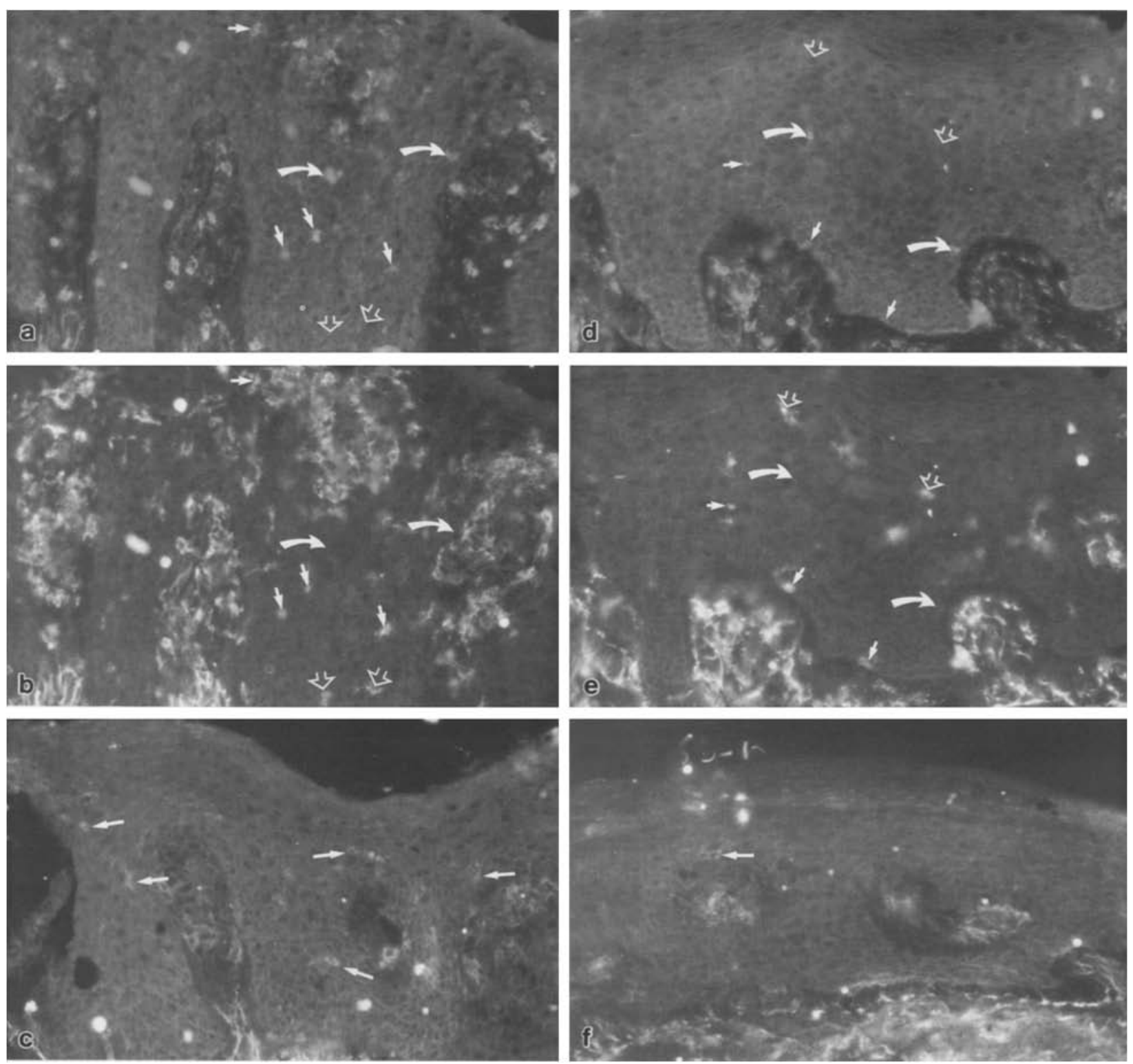

Fig. 5a-f. Distribution of immunocytes at pretherapy $a-c$ and after 7 days of CsA therapy $\mathbf{d}-\mathbf{f}$; original magnification $\times 50$. a Leu1 ${ }^{+}$(T cells) and $\mathbf{b ~ D R}{ }^{+}$cells in psoriasis skin at pretherapy. Small arrows denote cells expressing both Leu1 a and HLA-DR b (Leu1 ${ }^{+} \mathrm{DR}^{+}$cells; activated $\mathrm{T}$ cells). Curved arrows denote cells expressing Leu1 a but not HLA-DR b $\left(\right.$ Leu $^{+}{ }^{+} \mathrm{DR}^{-}$cells; non-activated $\mathrm{T}$ cells). Open arrows denote cells expressing HLA$\mathrm{DR}$ b but not Leu1 a (Leu1 ${ }^{-} \mathrm{DR}^{+}$cells). These include Langerhans cells and macrophages. $\mathbf{c}$ Mono $1^{+}$monocytic cells

appears that clearing of immune cells occurs at least concomitantly, and perhaps prior to clinical resolution.

Immune cells and their functions vary considerably in their sensitivity to CsA. To determine if there was selective disappearance of certain CsA sensitive cell types, the proportion of the different cell types at

in psoriasis skin at pretherapy (small arrows). d Marked decrease in Leu1 ${ }^{+}$( $\mathrm{T}$ cells) and e DR ${ }^{+}$cells at day 7 of CsA therapy. Small arrows denote cells expressing both Leu1 a and HLA-DR b (Leul ${ }^{+} \mathrm{DR}^{+}$cells; activated $\mathrm{T}$ cells). Curved arrows denote cells expressing Leu1 a but not HLA-DR b (Leu ${ }^{+} \mathrm{DR}^{-}$cells; non-activated T cells). Open arrows denote cells expressing HLA$\mathrm{DR}$ b but not Leu1 a (Leu1- DR ${ }^{+}$cells). These include Langerhans cells and macrophages. f Very few monocytes remain at day 7 of CsA therapy (small arrows)

various times during treatment was determined relative to the corresponding total number of leukocytes. There was no significant difference between baseline and day 7 of therapy in the number of $\mathrm{Mono}^{+}$monocytes expressed as a percentage of the total number of leukocytes in the lesion (Table 1). The same was true for Leu $1^{+} \mathrm{T}$ cells, activated $\mathrm{T}$ cells $\left(\mathrm{Leu} 1^{+} \mathrm{DR}^{+}\right)$and 
Table 1. Leukocyte subsets at pretherapy (day 0 ) and 7 days of CsA therapy expressed as a percentage of the total number of leukocytes in the psoriatic lesion

\begin{tabular}{|c|c|c|c|c|c|c|}
\hline \multirow[t]{2}{*}{ Phenotype } & \multicolumn{3}{|l|}{ Epidermis } & \multicolumn{3}{|l|}{ Dermis } \\
\hline & Day $0^{\mathrm{a}}$ & Day 7 & $p$ value $^{\mathbf{b}}$ & Day 0 & Day 7 & $p$ value \\
\hline Mono1 $^{+}$ & $39.0 \pm 1.6^{\mathrm{c}}$ & $43.0 \pm 0.6$ & $\mathrm{NS}^{\mathrm{d}}$ & $48.0 \pm 3.0$ & $49.4 \pm 2.5$ & NS \\
\hline Leu $^{+}$ & $37.0 \pm 0.9$ & $32.8 \pm 1.6$ & $\mathrm{NS}$ & $49.4 \pm 3.4$ & $43.2 \pm 1.5$ & NS \\
\hline Leu1 ${ }^{+} \mathrm{DR}^{+}$ & $16.0 \pm 5.4$ & $17.6 \pm 3.8$ & NS & $21.4 \pm 2.5$ & $25.2 \pm 4.0$ & NS \\
\hline $\mathrm{CD}^{+}{ }^{+} \mathrm{DR}^{+}$ & $24.2 \pm 1.1$ & $24.0 \pm 1.6$ & NS & $7.2 \pm 0.6$ & $7.2 \pm 1.0$ & NS \\
\hline $\mathrm{CD}^{-}{ }^{-} \mathrm{DR}^{+}$ & $28.2 \pm 1.9$ & $19.6 \pm 1.5$ & 0.04 & $53.8 \pm 5.4$ & $45.0 \pm 2.6$ & NS \\
\hline
\end{tabular}

a Day of biopsy following onset of therapy with CsA

b Values refer to changes between baseline and day 7 of CsA therapy

c Values expressed as a percentage mean \pm SEM of 6 patients

d NS, Not significant $(p>0.05)$

$\mathrm{CD}^{+} \mathrm{DR}^{+}$LCs (Table 1). For the phenotype $\mathrm{CD} 1^{-} \mathrm{DR}^{+}$in the epidermis, there was a significant decrease $(p=0.04)$ in the number of cells of this subtype expressed as a percentage of total leukocytes between days 0 and 7 of therapy, confirming that LCs tended to emerge as the predominant $\mathrm{DR}^{+}$cell in treated epidermis (Table 1).

\section{Discussion}

There is a marked difference in the composition of the various cell types in psoriatic epidermis and dermis compared with normal skin. Bone marrow derived cells in the normal human epidermis consist almost entirely of LCs [4-6]. These LCs normally comprise $1 \%-4 \%$ percent of the total epidermal population $[5,7]$. In our untreated patients, leukocytes in the epidermis of involved psoriasis skin were composed of $\mathrm{CD}^{+}{ }^{+} \mathrm{DR}^{+}$LCs, Mono1 ${ }^{+}$macrophages and Leu1 ${ }^{+}$ cells (Fig. 1). In a study by Baker et al. [10], epidermal leukocytes in psoriasis skin were also elevated and contained both $\mathrm{T}$ cells and $\mathrm{DR}^{+}$dendritic cells $\left(\mathrm{CD} 1^{+} \mathrm{DR}^{+} \mathrm{LCs}\right.$ and $\mathrm{CD} 1^{-} \mathrm{DR}^{+}$epidermal cells). Utilizing epidermal cell suspensions, we have previously shown that psoriatic epidermal cells contain an elevated capacity to activate $T$ cells [8]. The $\mathrm{CD}^{-} \mathrm{DR}^{+}$cells in psoriatic epidermis appear to be antigen presenting cells, since both $\mathrm{CD} 1^{-} \mathrm{DR}{ }^{+}$cells as well as $\mathrm{CD} 1{ }^{+} \mathrm{DR}{ }^{+} \mathrm{LCs}$, were critical for the induction of $\mathrm{T}$ cell activation [8]. In the normal dermis, bone marrow derived cells are usually comprised of monocytes and macrophages [9], as well as a small number of T cells [10]. We found that leukocytes in the dermis of psoriatic plaques consisted of approximately equal proportions of T cells and cells of the monocyte/ macrophage series, along with an increased proportion of $\mathrm{CD} 1^{+} \mathrm{DR}{ }^{+} \mathrm{LCs}$ (which are only rarely present in normal dermis). Other authors $[11,12]$ have also found that the dermal infiltrate in early and fully developed psoriatic lesions consists mostly of $T_{\text {. }}$ lymphocytes and macrophages, with the former being the predominant cell type.

CsA therapy caused a marked decrease in the intensity of the immunocytic infiltrate in both the epidermis and dermis. There was a significant decrease in the number of all subsets of leukocytes and in epidermal HLe1 ${ }^{-} \mathrm{DR}^{+}$keratinocytes. However, the proportion of $\mathrm{T}$ cells, activated $\mathrm{T}$ cells, monocytes, $\mathrm{CD} 1^{+} \mathrm{DR}^{+}$ LCs and dermal $\mathrm{CD} 1^{-} \mathrm{DR}{ }^{+}$cells in relation to the total number of leukocytes was unchanged with therapy, reflecting equally proportionate losses of each subtype (Table 1). The reduction in the absolute numbers of total leukocytes, $\mathrm{T}$ cells, activated $\mathrm{T}$ cells, monocytes and $\mathrm{CD} 1^{+} \mathrm{DR}^{+} \mathrm{LCs}$ was rapid, with a large proportion of the change occurring within 3 days. The rapidity of the CsA effect on leukocyte reduction is consistent with the concept that the immune effects of CsA are important in the mechanism of CsA clearing of psoriasis, since leukocyte reduction either preceded or coincided with clinical improvement.

In psoriatic epidermis, using double immunofluorescence techniques to visualize CD1 and HLA-DR, we found that the absolute numbers of LCs decreased with CsA therapy, with the number and pattern of LCs in treated psoriatic epidermis being similar to that of normal skin. Much attention has been focused on the number and location of LCs in psoriasis; however, it remains controversial as to whether LCs in psoriasis lesions as assessed in vertical sections are increased relative to normal [13] or uninvolved psoriasis skin $[13,14]$, or decreased compared with normal $[15,16]$ or uninvolved psoriasis skin [14]. Comparison of epidermal LCs density obtained by various authors [14$19]$ is difficult because of the large numbers of methods used to quantitate LCs in sections $[2,14,15,17,20$, 
21]. Utilizing epidermal cell suspensions to quantitate $\mathrm{CD} 1{ }^{+} \mathrm{DR}{ }^{+} \mathrm{LCs}$ in relation to keratinocytes, we found no significant difference in the percentage of Langerhans cells in psoriasis epidermis relative to uninvolved epidermis [8]. As reported by Bos et al. [22], we found that LCs are present in significantly increased numbers in the dermis in untreated lesions of psoriasis (Fig. 3), since LCs are only rarely present in normal dermis $[10,23]$. The presence of dermal LCs in untreated psoriatic lesional skin supports the concept of psoriatic skin harboring a form of an ongoing cellular immune response. Significant numbers of dermal LCs are generally only found in the context of cellular immune responses in the skin (for example, allergic contact dermatitis) [24] or in cutaneous T-cell lymphoma [25].

Unlike normal skin which lacks epidermal $\mathrm{CD} 1^{-} \mathrm{DR}^{+}$cells $[8,22]$, in lesional psoriatic skin $\mathrm{CD} 1^{-} \mathrm{DR}^{+}$cells were present in the epidermis at day 0 . $\mathrm{CD}^{-}{ }^{-} \mathrm{DR}^{+}$cells in the epidermis of psoriatic skin are heterogenous [8] and contain a variety of $\mathrm{DR}^{+}$ cells, including activated $\mathrm{T}$ cells $\left(\mathrm{DR}^{+} \mathrm{T}\right.$ lymphocytes), activated keratinocytes ( $\mathrm{DR}^{+}$keratinocytes), $\mathrm{DR}^{+}$monocytes and non-LCs dendritic APC $[1,8,23]$. $\mathrm{CD} 1^{-} \mathrm{DR}^{+}$dendritic cells may contain immature LCs, since Birbeck granules have been found in certain of these cells [9]. However, psoriasis epidermal $\mathrm{CD} 1^{-} \mathrm{DR}^{+}$cells may be analogous to nonLangerhans $\mathrm{CD}^{-} \mathrm{DR}^{+}$cells, reported following UVB and UVC radiation, that are potent stimulators of immunoregulatory self-T cells in the absence of added antigen [26-29]. In fact, Schopf et al. [30] have demonstrated that epidermal cells from lesional psoriatic skin are significantly more active in stimulating autologous $\mathrm{T}$ cell proliferation compared with cells from uninvolved psoriatic or normal epidermis. Since $\mathrm{CD}^{-}{ }^{-} \mathrm{DR}^{+}$epidermal cells are involved in the enhanced antigen presenting activity of psoriasis epidermal cells [8], the $\mathrm{CD} 1{ }^{-} \mathrm{DR}^{+}$population may be critical for initiating $\mathrm{T}$-cell activation and inflammatory lymphokine release in psoriasis skin.

In the epidermis by day 7 of therapy, both the absolute numbers of $\mathrm{CD}^{-}{ }^{-} \mathrm{DR}{ }^{+}$cells (Fig. 1) as well as the proportion of these cells as a percentage of total leukocytes at day 7 was decreased (Table 1). We also noted a dramatic loss of $\mathrm{CD} 1^{-} \mathrm{DR}^{+}$cells as well as antigen presenting cell function, in psoriasis epidermis during CsA therapy when quantitated using epidermal cell suspensions [31]. Epidermal non-Langerhans $\mathrm{CD} 1^{-} \mathrm{DR}^{+}$cells demonstrated a proportionally greater decrease compared to epidermal $\mathrm{CD} 1^{+} \mathrm{DR}{ }^{+}$ $\mathrm{LCs}$ with the ratio of $\mathrm{CD} 1^{+} \mathrm{DR}{ }^{+} \mathrm{LCs} / \mathrm{non}^{-}$ Langerhans $\mathrm{CD}^{-}{ }^{-} \mathrm{DR}^{+}$epidermal cells changing from a mean of 0.82 to 1.92 at day 14. Thus, CsA appears to be effective at clearing $\mathrm{CD} 1^{-} \mathrm{DR}^{+}$cells while leaving Langerhans cells relatively intact in the epidermis.

Our findings of a rapid reduction in T-cell numbers in psoriasis skin following CsA therapy are consistent with a role for $T$ cells and their lymphokines in psoriasis. Double staining with anti-HLe1 and anti-HLA DR or anti-Leu1 and anti-HLA DR monoclonal antibodies confirmed that in lesional psoriatic epidermis, $\mathrm{DR}^{+}$keratinocytes are present in the vicinity of $\mathrm{T}$ cells in a basilar position $[18,32]$.

Psoriasis skin contains increased numbers of monocytes, Langerhans cells, and T cells, and shows evidence of an ongoing cellular immune reaction. CsA may cause improvement of psoriasis by interfering with immune cell activation in the skin. This is supported by the decreased numbers of inflammatory cells in both the epidermis and dermis, and evidence of reduced production of proinflammatory cytokines early in the course of treatment with CsA.

Acknowledgements. We would like to thank Mr. T. Hamilton for carrying out the statistical analysis and Mr. D. McQuaid and Mr. K. Sadkowski for typing the manuscript. The cyclosporin was supplied by Sandoz Pharmaceuticals, East Hanover, New Jersey, USA.

\section{References}

1. Ellis CN, Gorsulowsky DC, Hamilton TA, Billings JK, Brown MD, Headington JT, Cooper KD, Baadsgaard O, Duell EA, Annesley TM, Turcotte JG, Voorhees JJ (1986) Cyclosporine improves psoriasis in a double-blind study. $J$ Am Med Assoc 256:3110-3116

2. Baker BS, Griffiths CEM, Lambert S, Powles AV, Leonard JN, Valdimarsson H, Fry L (1987) The effects of cyclosporin $A$ on $T$ lymphocyte and dendritic cell sub-population in psoriasis. Br J Dermatol 116:503-510

3. de Jong MCJM, Blanken R, Nanninga J, Van Voorst Vader PC, Poppema $S$ (1986) Defined in situ enumeration of T6 and HLA-DR expressing epidermal Langerhans cells: morphologic and methodologic aspects. $J$ Invest Dermatol $87: 698-702$

4. Andrew W, Andrew NV (1949) Lymphocytes in the normal epidermis of the rat and of man. Anat Rec 104:217-242

5. Cooper KD, Breathnach SM, Caughman SW, Palini AG, Waxdal MJ, Katz SI (1985) Fluorescence microscopic and flow cytometric analysis of bone marrow-deprived cells in human epidermis: a search for the human analogue of the murine dendritic Thy-1 ${ }^{+}$epidermal cell. J Invest Dermatol $85: 546-552$

6. Morhenn VB, Mahrle G (1981) Expression of HLA-DR antigen on skin cells in psoriatic plaques. Clin Res 29:608A

7. Stingl G, Katz SI, Clement L, Green I, Shevach EM (1978) Immunologic functions of Ia-bearing epidermal Langerhans cells. J Immunol $121: 2005-2013$

8. Baadsgaard O, Gupta A, Ellis $\mathrm{CN}$, Voorhees JJ, Cooper KD (1989) Psoriasis epidermal cells demonstrate increased numbers and function of non-Langerhans cell antigen presenting cells. J Invest Dermatol 92:190-195

9. Poulter LW, Seymour GJ, Duke O, Janossy G, Panayi G (1982) Immunohistochemical analysis of delayed-type hypersensitivity in man. Cell Immunol 74:358-369 
10. Bos JD, Zoneveld I, Das PK, Krieg SR, van der Loos CM, Kapsenberg ML (1987) The skin immune system (SIS): distribution and immunophenotype of lymphocyte subpopulators in normal human skin. J Invest Dermatol $88: 569-573$

11. Bjerke JR (1982) In situ characterization and counting of mononuclear cells in lesions of different clinical forms of psoriasis. Acta Dermatol Venereol (Stockh) 62:93-100

12. Bjerke JR, Krogh TK, Matre (1978) Characterization of mononuclear cell infiltrates in psoriatic lesions. $J$ Invest Dermatol $71: 340-343$

13. Baker BS, Swain AF, Griffiths CEM, Leonard JN, Fry L, Valdimarsson $\mathrm{H}$ (1985) The effects to topical treatment with steroids or dithranol on epidermal $\mathrm{T}$ lymphocytes and dendritic cells in psoriasis. Scand J Immunol 22:471 - 477

14. Ashworth J, Turbitt ML, Mackie R (1986) The distribution and quantification of the epidermis. Clin Exp Dermatol $11: 153-158$

15. Haftek M, Faure M, Schmitt D, Thivolet J (1983) Langerhans cells in skin from patients with psoriasis: quantitative and qualitative study of T6 and HLA-DR antigenexpressing cells and changes with aromatic retinoid administration. J Invest Dermatol $81: 10-14$

16. Lisi $P$ (1973) Investigation on Langerhans cells in pathological human epidermis. Acta Derm Venereol (Stockh) $53: 425-428$

17. Baker BS, Swain AF, Fry L, Valdimarsson H (1984) Epidermal $\mathrm{T}$ lymphocytes and HLA-DR expression in psoriasis. Br J Dermatol 110:555-564

18. Morhenn VB, Abel EA, Mahrle G (1982) Expression of HLA-DR antigen in skin from patients with psoriasis. J Invest Dermatol 78:165-168

19. Bos JD, Hulsebosch HJ, Krieg SR, Bakker PM, Cormane RH (1983) Immunocompetent cells in psoriasis. Arch Dermatol Res 275:181-189

20. Harrist TJ, Mahlbauer JE, Murphy GF, Mihm MC, Bhan AK (1983) T6 is superior to Ia (HLA-DR) as a marker for Langerhans cells and indeterminate cells in normal epidermis: a monoclonal antibody study. J Invest Dermatol $80: 100-103$

21. Horton JJ, Allen MH, MacDonald DM (1986) An assessment of Langerhans cell quantification in tissue section. J Am Acad Dermatol 11:591-593

22. Bos JD, van Garderen ID, Krieg SR, Poulter LW (1986) Different in situ distribution patterns of dendritic cells having Langerhans $\left(\mathrm{T}^{+}\right)$and interdigitating (RFD1 $\left.{ }^{+}\right)$cell immunophenotype in psoriasis, atopic dermatitis, and other inflammatory dermatoses. J Invest Dermatol 87:358-361

23. Alegre VA, Mac Donald DM, Poulter LW (1986) The simultaneous presence of Langerhans cell and interdigitating cell antigenic markers on inflammatory dendritic cells. Clin Exp Immunol 64:330-333

24. Marks JG Jr, Zaino RJ, Bressler MF, Williams JV (1987) Changes in lymphocyte and Langerhans cell populations in allergic and irritant contact dermatitis. Int J Dermatol $26: 354-357$

25. Jimbow K, Chiba M, Horikoshi T (1982) Electron microscopic identification of Langerhans cells in the dermal infiltrates of mycosis fungoides. J Invest Dermatol 78:102

26. Cooper KD, Fox P, Neises GR, Katz SI (1985) Effects of ultraviolet radiation on human epidermal cell alloantigen presentation: Initial depression of Langerhans cell dependent function is followed by the appearance of $\mathrm{T}^{-} \mathrm{DR}^{+}$ cells that enhance epidermal alloantigen presentation. $\mathrm{J}$ Immunol 134:129-137

27. Cooper KD, Neises GR, Katz SI (1986) Antigen presenting $\mathrm{OKM}^{+}$melanophages appear in human epidermis after ultraviolet radiation. J Invest Dermatol 86:363-370

28. Baadsgaard O, Wulf HC, Wantzin GL, Cooper KD: UVB and UVC, but not UVA, potently induce the appearance of $\mathrm{T}^{-}{ }^{-} \mathrm{DR}{ }^{+}$antigen-presenting cells in the human epidermis. J Invest Dermatol 89:113-118

29. Baadsgaard O, Fox DA, Cooper KD (1988) Human epidermal cells from ultraviolet light-exposed skin preferentially activate autoreactive $\mathrm{CD} 4{ }^{+} 2 \mathrm{H} 4^{+}$suppressor-induced lymphocytes and $\mathrm{CD}^{+}$suppressor/cytotoxic lymphocytes. J Immunol 140:1738-1744

30. Schopf RE, Jung HM, Morsches B, Bork K (1986) Stimulation of $T$ cells by autologous mononuclear leukocytes and epidermal cells in psoriasis. Arch Dermatol Res 279: $89-94$

31. Cooper KD, Baadsgaard O, Gupta A, Billings J, Brown M, Ellis C, Voorhees JJ (1987) Phenotype and function of cyclosporin A-sensitive epidermal immunocompetent cells in psoriasis. Clin Res $35: 387 \mathrm{~A}$

32. Gottlieb AB, Lifshitz B, Fu SM, Staino-Coico L, Wang CY, Carter DM (1986) Expression of HLA-DR molecules by keratinocytes, and presence of Langerhans cells in the dermal infiltrate of active psoriatic plaques. J Exp Med $164: 1013-1028$

Received October 6, 1988 